\title{
PENGARUH SOSIALISASI KADER POSYANDU TERHADAP PENINGKATAN PENGETAHUAN TENTANG IMD DAN ASI EKSKLUSIF
}

\author{
Septya Rosa, Maiza Duana \\ Universitas Teuku Umar Aceh, Indonesia \\ Email: septyarosa999@gmail.com,maizaduana@utu.ac.id
}

\begin{abstract}
Abstrak
Pemberian Inisiasi Menyusu Dini (IMD) pada bayi usia $<0-6$ dan pemberian Asi Eksklusif sampai umur 2 tahun telah ramai di lakukan oleh masyarakat, namun masih terdapat masalah kesehatan yang dijumpai di Kecamatan Tujuan penelitian ini adalah untuk mengetahui peningkatan pengetahuan tentang IMD dan asi eksklusif sebelum dan sesudah sosialisasi metode slide ceramah pada kader posyandu di kecamatan seunagan. Metode penelitian Kuantitatif dengan desain Quasi Eksperimen dengan cara pre-test and post-test, Populasi dalam penelitian ini adalah 35 kader posyandu, Penentuan sampel dilakukan dengan total sampling menggunakan kriteria inskusi dan eksklusi sehingga jumlah kader menjadi 35 kader posyandu. Analisis data menggunakan Univariat, Bivariat dengan Uji Wilcoxon. Hasil penelitian ini dengan nilai pre-test 3,09 nilai post-test 6,09 dan nilai PValue 0,000. Kesimpulan penelitian ini yaitu sosialisasi kader posyandu terhadap peningkatan pengetahuan IMD dan asi eksklusif dengan metode slide ceramah efektif dan berpengaruh. Saran kepada kader posyandu untuk lebih tingkatkan lagi pengetahuan IMD dan asi eksklusif, ketika berada di lapangan sudah lebih siap dalam menghadapi masyarakat.
\end{abstract}

Kata Kunci: Sosialisasi; Pengetahuan Kader; IMD; Asi Eksklusif

\section{Abstract}

The provision of Early Breastfeeding Initiation (IMD) in infants aged 0-6 and exclusive breastfeeding until the age of 2 years has been widely done by the community, but there are still health problems found in the District The purpose of this study is to find out the increase in <knowledge about IMD and exclusive breast milk before and after the socialization of the method of slide lectures on posyandu cadres in seunagan sub-district. Quantitative research method with Quasi Experimental design by pre-test and post-test, Population in this study is 35 posyandu cadres, Sample determination is done by total sampling using criteria of inscusion and exclusion so that the number of cadres becomes 35 posyandu cadres. Data analysis using Univariate, Bivariate with Wilcoxon Test. The results of this study with a pre-test value of 3.09 post-test value 6.09 and PValue value of 0.000 . The conclusion of this study is the socialization of posyandu cadres to increase exclusive IMD and breast milk knowledge with effective and influential lecture slide methods. Advice to posyandu cadres to further increase exclusive IMD and breast milk knowledge, when in the field is better prepared in facing the community.

Keywords: Socialization; Knowledge of Cadres; IMD and Exclusive Breast Milk

$\begin{array}{ll}\text { How to cite: } & \text { Rosa, S., Duana, M., (2022) Pengaruh Sosialisasi Kader Posyandu Terhadap Peningkatan Pengetahuan } \\ & \text { Tentang IMD dan Asi Eksklusif, Syntax Idea, 4(1), https://doi.org/10.36418/syntax-idea.v4i1.1692 } \\ \text { E-ISSN: } & \text { 2684-883X } \\ \text { Published by: } & \text { Ridwan Institute }\end{array}$




\section{Received: 2021-12-22; Accepted: 2022-01-05; Published: 2022-01-20}

\section{Pendahuluan}

Dinas Kesehatan Nagan Raya, Laporan di puskesmas jeuram kecamatan seunagan dari 199 jumlah bayi baru lahir terdapat hanya 1 bayi yang melakukan Inisiasi Menyusui Dini 1\% dan Pemberian Asi Eksklusif pada bayi 0-6 yang berjumlah 125 terdapat 49 bayi yang mengkonsumsi Asi Eksklusif, terdapat 39\% yang mencakup Asi Eksklusif, target cakupan IMD tahun 2020 54\% sedangkan target cakupan ASI Eksklusif tahun 2020 40\% target yang diinginkan untuk IMD dan Asi Eksklusif juga masih jauh dari target Rencana Strategis (Renstra) kemenkes tahun 2020-2024 yang menetapkan target pencapaian IMD sebesar 70-80\% (Widiyanto, 2012).

ASI adalah air susu ibu yang mengandung nutrisi optimal, baik kualitas dan kuantitasnya. Pemberian ASI merupakan metode emberian makan bayi yang terbaik (Sulistiyowati \& Siswantara, 2014).

Pemberian Air Susu Ibu (ASI) pada bayi saat ini telah banyak dilakukan oleh masyarakat dunia. Inisiasi menyusui dini (IMD) terdapat kolostrum yang merupakan makanan yang sangat tepat dan baik bagi bayi hingga usia 0-6 bulan dan dilanjutkan pemberian ASI sampai umur 2 tahun (Simbung \& Ohorella, 2021).

Cakupan Bayi Secara Nasional mendapat ASI eksklusif pada tahun 2019 adalah sebesar $67,74 \%$ atau dari 2.943.615 bayi usia < 6 bulan, 1.994 .097 bayi mendapatkan ASI Eksklusif. Angka tersebut sudah melampaui batas target Renstra tahun 2019 yaitu 50\%. Cakupan ASI eksklusif persentase tertinggi terdapat pada provinsi Nusa Tenggara Barat (86,26\%), dan persentase terendah di Provinsi Papua Barat (41,12\%). Tahun 2019 terdapat empat provinsi yang belum mencapai target Restra, yaitu Gorontalo, Maluku, Papua, dan Papua Barat. Meskipun target Restra sudah mencapai 50\%, namun angka cakupan ASI Eksklusif sebesar 67,74\% masih jauh dari target yang dicanangkan oleh Kementrian Kesehatan yaitu sebesar 80\% (Kambera, Pratiwi, Yanuarti, Oktarianita, \& Wati, 2021).

Pada tahun 2017 World Health Organization (WHO) melaporkan angka inisiasi menyusu dini (IMD) 51\% per 1000 hari kelahiran. Inisiasi menyusu dini (IMD) pada tahun 2018 terjadi kenaikan yaitu 60\% per 1000 kelahiran hasil yang ingin dicapai 100\%. Di harapkan pada tahun 2019 sudah mampu mencapai 100\%. Asi Eksklusif pada tahun 2017 dilaporkan adanya 1300 bayi usia 0-6 bulan dan 1000 bayi terdapat yang tidak mendapatkan Asi Ekslusif dan tergolong dalam permasalahan masyarakat. Hal ini diperparah dengan meningkatnya presentase pemberian susu formula dibandingkan ASI Eksklusif pada tahun 2018 yaitu terdapat 1600 bayi usia 0-6 bulan dan Hubungan pelaksanaan IMD dan pemberian Asi Eksklusif (Alwi \& Asrina, 2021).

Berdasarkan Data Survey Demografi dan Kesehatan Indonesia Provinsi Aceh tahun 2018 bahwa praktik pemberian ASI Eksklusif hanya 15\% anak berumur di bawah 6 bulan mendapatkan ASI eksklusif (Aceh, 2018). Sedangkan menurut profil Kesehatan 
Aceh tahun 2019 sebesar 55\% yang terjadi penurunan dari tahun sebelumnya sebesar $61 \%$ (Kemenkes RI, 2018).

Berdasarkan hasil data dari Dinas Kesehatan Nagan Raya, Laporan di puskesmas jeuram kecamatan seunagan dari 199 jumlah bayi baru lahir terdapat hanya 1 bayi yang melakukan Inisiasi Menyusui Dini 1\% dan Pemberian Asi Eksklusif pada bayi 0-6 yang berjumlah 125 terdapat 49 bayi yang mengkonsumsi Asi Eksklusif, terdapat 39\% yang mencakup Asi Eksklusif, target cakupan IMD tahun 2020 54\% sedangkan target cakupan ASI Eksklusif tahun 2020 40\% target yang diinginkan untuk IMD dan Asi Eksklusif juga masih jauh dari target Rencana Strategis (Renstra) kemenkes tahun 2020-2024 yang menetapkan target pencapaian IMD sebesar 70-80\%.

Berdasarkan hasil survei dinas kesehatan dan wawancara kader didapatkan permasalahan yang menghambat masih rendahnya cakupan IMD yang jauh dari target. meskipun target capaian Asi Eksklusif di Kecamatan Seunagan Kabupaten Nagan Raya sudah mencapai target bisa saja terjadi penurunan di tahun 2021 dikarenakan sampai sekarang masih terdapat masalah, antara lain : masih terdapat kader posyandu yang tidak melakukan penyuluhan terhadap IMD dan asi eksklusif karena terbatas pengetahuan yang dimiliki, kurangnya kunjungan kader kerumah-rumah untuk memberikan pemahaman mengenai IMD dan ASI Eksklusif dan Masalah yang menjadi penghambat IMD yang tidak berjalan yaitu kurangnya konseling oleh tenaga Kesehatan dan kurangnya praktek IMD dikarenakan bayi yang lahir di rumah sakit atau klinik secara SC (Seksio Sesarea) tidak IMD sehingga IMD tidak dilakukan asi eksklusif akan jarang berhasil, serta kurangnya kepedulian terhadap pentingnya IMD.

Setelah dilakukan intervensi kepada kader melalui Sosialisasi yang di berikan di dinkes Nagan Raya. mengingat pentingnya permasalahan ini bagi masyarakat Aceh terutama daerah Nagan Raya, Khususnya wilayah Seunagan salah satu cara yang diharapkan untuk dapat mengatasi masalah tersebut ialah dengan cara pendekatan yang strategis diperlukan untuk meningkatkan pengetahuan gizi tentang IMD dan Asi Eksklusif pada kader posyandu agar tercapai hasil maksimal ketika berada di lapangan untuk melakukan sosialisasi atau penyuluhan kepada ibu bayi atau balita menggunakan metode slide ceramah.

Berdasarkan uraian latar belakang di atas, maka peneliti tertarik untuk melakukan penelitian dengan judul "Pengaruh Sosialisasi Kader Posyandu Terhadap Peningkatan Pengetahuan IMD Dan Asi Eksklusif Di Kecamatan Seunagan Kabupaten Nagan Raya”.

\section{Metode Penelitian}

Metode penelitian ini menggunakan metode kuantitatif. Jenis penelitian ini adalah Quasi eksperimen (rancangan eksperimen semu) dengan desain pretest and posttes, yang dapat digambarkan sebagai berikut (Notoatmodjo, 2012):

Kelompok Eksperimen: $\mathrm{O} 1 \longrightarrow \mathrm{Xa} \longrightarrow \mathrm{O} 2$

Keterangan :

$\mathrm{Xa}=$ Pemberi Sosialisasi dengan media slide 
$\mathrm{O} 1=$ rerata pretest kelompok eksperimen

$\mathrm{O} 2=$ rerata posttest kelompok eksperimen

Dalam hal ini untuk mengetahui peningkatan pengetahuan kader tentang IMD dan ASI Eksklusif di Kecamatan Seunagan, Kabupaten Nagan Raya.

Pelaksanaan penelitian dilakukan di Dinas Kesehatan Nagan Raya pada masa magang mahasiswa selama satu semester ( 6 bulan). Waktu penelitian bersamaan dengan kegiatan yang dilaksanakan pihak dinkes dimulai dari 13 Oktober 2021 yaitu melakukan pretest dan sosialisasi, tanggal 15 Oktober 2021 melakukan posttest.

Populasi dalam penelitian ini adalah perwakilan kader yang terdata di posyandu Kecamatan Seunagan sebanyak 35 orang dan bersedia mengikuti sosialisasi (Notoatmodjo, 2012).

\section{Hasil dan Pembahasan}

\section{A. Hasil Penelitian}

\section{Karakteristik Data Responden Penelitian}

Berdasarkan hasil pengumpulan data penelitian yang telah peneliti lakukan terhadap 35 responden yang berada di Kecamatan Seunagan Kabupaten Nagan Raya, maka diperoleh karakteristik data berdasarkan umur sebagai berikut.

Tabel 1

Karakteristik Data Berdasarkan Umur

\begin{tabular}{cccc}
\hline NO & Kelompok Umur & Frekuensi & Persen \\
\hline 1 & 26 Tahun - 31 Tahun & 12 & 34,3 \\
\hline 2 & 32 Tahun - 37 Tahun & 14 & 74,3 \\
\hline 3 & 38 Tahun - 40 Tahun & 9 & 25,7 \\
& Total & $\mathbf{3 5}$ & $\mathbf{1 0 0}$ \\
\hline
\end{tabular}

Sumber: Data Primer (Diolah Tahun 2021)

Berdasarkan Tabel 1 mengenai karakteristik responden berdasarkan umur, maka dapat diketahui umur kader posyandu di Kecamatan Seunagan Kabupaten Nagan Raya, umur responden 31 Tahun yaitu sebanyak 12 responden atau sebesar 34,3\%. Responden berumur 32 Tahun 37 Tahun sebanyak 14 responden atau sebesar 74,3\%. Responden 38 Tahun ada sebanyak 9 orang atau sebesar 25,7\%. 


\section{Analisis Univariat}

Tabel 2

Distribusi Frekuensi Pengetahuan Responden Tentang IMD dan ASi

Eksklusif di Kecamatan Seunagan Kabupaten Nagan Raya

\begin{tabular}{lcccc}
\hline \multirow{2}{*}{ Pengetahuan } & \multicolumn{2}{c}{ PreTest } & \multicolumn{2}{c}{ Post Test } \\
\cline { 2 - 5 } & Frekuensi & Persen & Frekuensi & Persen \\
\hline Baik & 6 & 17,1 & 31 & 88,6 \\
\hline Cukup & 4 & 11,4 & 2 & 5,7 \\
\hline Kurang Baik & 25 & 71,4 & 2 & 5,7 \\
\hline Total & $\mathbf{3 5}$ & $\mathbf{1 0 0}$ & $\mathbf{3 5}$ & $\mathbf{1 0 0}$ \\
\hline
\end{tabular}

Sumber : Data Primer (Diolah Tahun 2021)

Berdasarkan tabel 2 diatas menunjukkan bahwa pre test pengetahuan responden yang pengetahuan baik sebanyak 6 responden $(17,1 \%)$, responden yang memiliki pengetahuan cukup sebanyak 4 responden $(11,4 \%)$ dan responden yang memiliki pengetahuan kurang baik sebanyak 25 responden (71,4\%). Sedangkan post test menunjukkan bahwa responden yang memiliki pengetahuan baik berjumlah 31 responden $(88,6 \%)$, responden yang memiliki pengetahuan cukup berjumlah 2 responden $(5,7 \%)$ dan responden yang memiliki pengetahuan kurang baik berjumlah 2 responden $(5,7 \%)$.

\section{Analisis Bivariat}

\section{1) Analisis Wilcoxon}

Tabel 3

Data Analisis Wilcoxon

\begin{tabular}{lccr}
\hline & N & Mean & P Value \\
\hline Pre Test_Pengetahuan & 35 & 3,09 & 0,000 \\
Post Test_Pengetahuan & 35 & 6,09 & \\
\hline
\end{tabular}

Sumber : Data Primer (Diolah Tahun 2021)

Dari hasil uji Wilcoxon Pengaruh Sosialisasi Kader Posyandu Terhadap Peningkatan Pengetahuan Tentang IMD dan Asi Eksklusif menggunakan Media Slide Ceramah Di Kecamatan Seunagan Kabupaten Nagan Raya sebanyak 35 responden diketahui bahwa nilai rata-rata post test $(6,09)$ lebih tinggi dari pada nilai rata-rata pre test $(3,09)$ dan diketahui bahwa P Value: $0,000 \square 0,05$ sehingga Ha diterima artinya secara statistic terdapat perbedaan peningkatan pengetahuan IMD dan asi eksklusif pada kader posyandu sebelum (pretets) dan sesudah (posttest) Pengaruh Sosialisasi Peningkatan Pengetahuan tentang IMD dan Asi Eksklusif Di Kecamatan Seunagan Kabupaten Nagan Raya. 


\section{B. Pembahasan}

Berdasarkan dari tabel 3 dapat diketahui bahwa sosialisasi metode slide ceramah terhadap peningkatan pengetahuan IMD dan asi eksklusif pada kader posyandu di kecamatan seunagan kabupaten nagan raya sebanyak 35 responden diketahui bahwa nilai rata-rata post test $(6,09)$ lebih tinggi dari pada nilai rata-rata pre test $(3,09)$ dan diketahui bahwa P Value: 0,0000,05 sehingga Ha diterima artinya secara statistik menunjukkan bahwa terdapat perbedaan peningakatan pengetahuan pengaruh sosialisasi tentang IMD dan asi eksklusif dengan menggunakan metode slide ceramah di kecamatan seunagan kabupaten nagan raya.

Adapun hasil posttest beberapa pertanyaan yang jumlahnya naik dijawab dengan benar dibandingkan dengan jawaban yang salah yaitu pertanyaan tentang di posyandu terdapat 5 kategori meja pada meja penyuluhan apa yg kader lakukan, terdapat 9 pesan $1000 \mathrm{Hpk}$ sebutkan dan jelaskan, definisi konselor asi, mengapa penting dilakukan konselor asi jelaskan. Sedangkan pertanyaan yang jumlahnya turun dijawab dengan benar dibandingkan dengan jawaban yang salah yaitu pertanyaan tentang definisi IMD, definisi asi eksklusif, usia berapa yang dikatakan asi eksklusif. Juga ada pertanyaan yang ketika dijawab sebelum sosialisasi dapat dijawab oleh kader posyandu tetapi sesudah dilakukan intervensi sosialisasi tidak dapat dijawab oleh kader posyandu.

Peningkatan pengetahuan membuktikan bahwa pengetahuan merupakan hasil dari seseorang yang menangkap informasi dengan penginderaan terhadap suatu objek, dimana penelitian ini responden diberikan sosialisasi satu arah dengan metode ceramah melalui media slide. Penelitian ini menjelaskan bahwa terdapat perbedaan yang cukup jelas mengenai tingkat pengetahuan sebelum dan sesudah sosialisasi. Hal ini juga seuai dengan penelitian mengenai penyerapan pengetahuan tentang kanker serviks sebelum dan sesudah penyuluhan (Wijayanti, Isnani, \& Kesuma, 2016).

Selain itu penelitian yang dilakukan oleh (Hidayati et al., 2019) tentang "pengaruh penyuluhan (ceramah dengan power point) terhadap pengetahuan tentang leptospirosis di kecamatan tambalang, kota semarang jawa tengah" membuktikan penyuluhan ceramah dengan power point menggunakan media lcd dapat meningkat pengetahuan tentang leptospirosis yang signifikan sebesar 0,694 dan kelompok control sebesar 0,205 sehingga dapat dikatakan mempunyai distribusi normal ( $\mathrm{p}$ 0,05). Analisis statistik Kruskall Wallis menunjukkan $\mathrm{p}$ value sebesar 0,000 ( $\mathrm{p}$ value $0,05)$ sehingga terjadi perbedaan rerata kenaikan skor kelompok control dengan kelompok intervensi tentang leptospirosis.

Didukung juga oleh penelitian terdahulu oleh (Rahayu Widaryanti, 2018) tentang "Intervensi Penyuluhan dengan Metode Ceramah dan Buzz untuk Peningkatan Pengetahuan dan Sikap Kader Posyandu dalam Pengendalian Rabies di Kabupaten Sukabumi” berdasarkan hasil penelitian setelah dilakukan penyuluhan, menunjukkan bahwa kelompok ceramah maupun kelompok buzz memiliki tingkat pengetahuan dan sikap yang sama sebelum dilakukan penyuluhan, skor post-test pengetahuan dan pre-test sikap pada kelompok ceramah maupun kelompok buzz juga 
tidak menunjukkan perbedaan yang nyata ( $\mathrm{p}$ 0,919 pengetahuan, $\mathrm{p}$ 0,952 sikap). Hal ini menunjukkan bahwa pengunaan metode ceramah maupun metode buzz dalam penyuluhan memberi hasil yang sama pada skor post-test pengetahuan dan sikap kader.

Selain itu dilakukan oleh penelitian terdahulu yang dilakukan oleh (Rahayu Widaryanti, 2018) dukungan tenaga kesehatan yang terlatih akan membantu keberhasilan pemberian ASI eksklusif. Jika ibu mengalami permasalahan dalam proses menyusui maka petugas kesehatan akan memberikan solusi sehingga meningkatkan cakupan ASI eksklusif.

Selain itu terdapat penelitian yang menyatakan bahwa IMD akan menentukan kesuksesan dalam pemberian ASI eksklusif, dimana ibu yang mendapatkan konseling mengenai IMD sebelum hamil dan selama hamil maka akan melakukan IMD dengan baik, sebaliknya ibu yang tidak menikah, melahirkan secara Sectio Caesarea (SC), dan tidak mendapatkan konseling mengenai IMD sebelum atau selama hamil maka saat melahirkan tidak melakukan IMD (Agusvina, 2015).

Dapat disimpulkan bahwa pengaruh sosialisasi kader posyandu terhadap peningkatan IMD dan asi eksklusif dengan menggunakan media slide ceramah merupakan peningkatan pengetahuan secara terencana pada individu, kelompok, maupun masyarakat dari tidak tahu tentang nilai yang terkandung di masyarakat khususnya IMD dan asi eksklusif menjadi tahu. Perubahan pengetahuan setelah diberikan sosialisasi metode slide ceramah pada kader posyandu sangat bermakna. Perubahan initerjadi disebabkan oleh factor-faktor yaitu : pemberian metode slide ceramah IMD dan asi eksklusif, disampaikan secara jelas dan tidak bertele-tele oleh narasumber dinkes yang sudah terlatih sehingga kader menerima informasi lebih jelas, intervensi sosialisasi menggunakan metode slide ceramah tentang imd dan asi eksklusif dimana metode dan media tersebut memperjelas pesan atau ide yang disampaikan, juga dapat mengingat kembali apa yang sudah disampaikan atau dapat membaca kembali dari slide yang sudah dibagikan secara online. Dalam media slide juga terdapat grafik atau gambar yang menjelaskan sosialisasi yang telah disampaikan. Materi yang disampaikan melalui sosialisasi metode ceramah persis dengan pertanyaan soal kusioner pretest dan postest, sehingga kader dapat langsung mengerti dan menjawab pertanyaan posttes dengan benar, informasi yang diberikan sesuai dengan kebutuhan kader posyandu, sehingga pada saat intervensi pemberian sosialisasi metode ceramah dan media slide kader posyandu antusias mendengar, melihat dan mendengar informasi yang disampaikan narasumber dinkes.

\section{Kesimpulan}

Dari hasil penelitian Pengaruh Sosialisasi Kader Posyandu Terhadap Peningkatan Pengetahuan Tentang IMD dan Asi Eksklusif di Kecamatan Seunagan Kabupaten Nagan Raya dapat disimpulkan bahwa, Sosialisasi dengan metode ceramah dan media slide terhadap peningkatan pengetahuan IMD dan asi eksklusif pada kader posyandu di kecamatan seunagan kabupaten nagan raya diras efektif dan berpengaruh, terlihat dari 
pengetahuan mereka setelah diberikan sosialisasi sangat meningkat, dimana metode ceramah dan media slide melibatkan banyak panca indra dan penulis merasa sosialisasi ini berpengaruh

\section{BIBLIOGRAFI}

Aceh, Dinkes. (2018). Profil Kesehatan Aceh Tahun 2017. Banda Aceh: Dinkes Aceh.

Agusvina, Revi. (2015). Hubungan inisiasi menyusu dini (IMD) terhadap keberhasilan ASI eksklusif di Posyandu Kelurahan Cempaka Putih Ciputat Timur. UIN Syarif Hidayatullah Jakarta: Fakultas Kedokteran Dan Ilmu Kesehatan, 2015. Google Scholar

Alwi, Muhammad Kidri, \& Asrina, Andi. (2021). Perbedaan Pengaruh Media Lembar Balik dan Kartu Kendali Edukasi Terhadap Pengetahuan Dan Sikap Ibu Menyusui Tentang ASI Ekslusif Di Wilayah Kerja Puskesmas Koppe Kabupaten Bone. Journal of Aafiyah Health Research (JAHR), 2(1), 91-102. Google Scholar

Hidayati, Fitri, Sudarnika, Etih, Latif, Hadri, Lukman, Denny Widaya, Ridwan, Yusuf, Zahid, Abdul, \& Wicaksono, Ardilasunu. (2019). Intervensi penyuluhan dengan metode ceramah dan buzz untuk peningkatkan pengetahuan dan sikap kader posyandu dalam pengendalian rabies di Kabupaten Sukabumi (in Bahasa). J. Penyul, 15, 65-74. Google Scholar

Kambera, Loli, Pratiwi, Bintang Agustina, Yanuarti, Riska, Oktarianita, Oktarianita, \& Wati, Nopia. (2021). Pengetahuan dan Sikap Ibu Menyusui Tentang Asi Eksklusif Pada Masa Pandemi Covid-19. Poltekita: Jurnal Ilmu Kesehatan, 15(3), 256-262. Google Scholar

Kemenkes RI. (2018). Pedoman Pekan Asi Sedunia (PAS) Tahun 2018. Direktorat Gizi Masyarakat.

Notoatmodjo, Soekidjo. (2012). Metodologi penelitian kesehatan. Google Scholar

Rahayu Widaryanti, Ian Rossalia P. P. (2018). Evaluasi Pasca Pelatihan Konseling Menyusui Terhadap Peningkatan Cakupan Asi Eksklusif Di Kota Yogyakarta. Medika Respati: Jurnal Ilmiah Kesehatan, 13(4), 9-16. Google Scholar

Simbung, Rismawati, \& Ohorella, Fadjriah. (2021). Pentingnya Iniasiasi Menyusu Dini (IMD) Pada Bayi Baru Lahir. MEGA PENA: Jurnal Pengabdian Kepada Masyarakat, 1(1), 21-25. Google Scholar

Sulistiyowati, Tutuk, \& Siswantara, Pulung. (2014). Perilaku Ibu Bekerja dalam Memberikan ASI Eksklusif di Kelurahan Japanan Wilayah Kerja Puskesmas Kemlagi Mojokerto. Jurnal Promkes, 2(1), 89-100. Google Scholar

Widiyanto, Subur. (2012). Hubungan pendidikan dan pengetahuan ibu tentang ASI 
eksklusif dengan sikap terhadap pemberian ASI eksklusif. UNIMUS. Google Scholar

Wijayanti, Tri, Isnani, Tri, \& Kesuma, Agung Puja. (2016). Pengaruh penyuluhan (ceramah dengan power point) terhadap pengetahuan tentang leptospirosis di Kecamatan Tembalang, Kota Semarang Jawa Tengah. Balaba: Jurnal Litbang Pengendalian Penyakit Bersumber Binatang Banjarnegara, 39-46. Google Scholar

\section{Copyright holder:}

Septya Rosa, Maiza Duana (2022)

First publication right:

Syntax Idea

This article is licensed under:

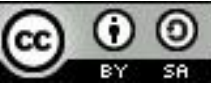

